\title{
AS CONCEPÇÕES DOS AGENTES DE EDUCAÇÃO INCLUSIVA SOBRE O PROCESSO DE INCLUSÃO ESCOLAR
}

\section{THE INCLUSIVE EDUCATORS' CONCEPTIONS ON THE SCHOOL INCLUSION PROCESS}

\author{
Jacyara de Oliveira Vanini ${ }^{1}$ \\ Tatiani de Oliveira Slesaczek ${ }^{2}$ \\ Fabiola Chesani ${ }^{3}$
}

\begin{abstract}
Resumo: O objetivo deste trabalho é analisar as concepções dos agentes de educação inclusiva no processo de inclusão escolar dos alunos com deficiência física e intelectual nas escolas de ensino regular de um município da região do Vale do Itajaí. Trata-se de uma pesquisa de abordagem qualitativa, exploratória e de campo. A técnica de coleta de dados foi realizada por meio de uma entrevista semiestruturada. Os dados foram examinados pela análise do conteúdo. Participaram do estudo 80 agentes de educação inclusiva. As categorias apontadas pelas educadoras relacionam-se a: inclusão de todos, Inclusão longe do ideal e do real, falta de recursos humanos e estrutura física para inclusão. As dificuldades existem e não são poucas, a inclusão não é apenas fazer com que o aluno esteja situado dentro de uma sala regular.
\end{abstract}

Palavras-chave: Educação inclusiva; ensino regular; educação continuada; educador inclusivo.

\begin{abstract}
The aim of this research is to analyze the conceptions by the agents of inclusive education in the process of school inclusion of students with physical and intellectual disabilities in ordinary schools of Itajai I SC. This is a qualitative, exploratory and field-based research. The technique of data collection was performed by a semi-structured interview. Data were examined by content analysis. 80 inclusive education agents participated in the study. The categories indicated by the educators are related to: inclusion of all, Inclusion far from the ideal and the real, lack of human resources and physical structure for inclusion. Difficulties exist and they are not few, since inclusion is not only to make the student situated within a regular classroom.
\end{abstract}

Keywords: Inclusive education; regular school; lifelong learning; inclusive educator.

\section{INTRODUÇÃO}

A inclusão no ensino regular enfrenta inúmeras dificuldades em diferentes aspectos, pois vivemos em uma sociedade na qual tudo é criado pensando-se em um indivíduo dito normal, gerando grande dificuldade para as pessoas com deficiência (de acordo com a Convenção sobre Direitos das Pessoas, realizada no ano de 2012), desde a acessibilidade à inclusão no ambiente educacional, que exige profissionais capacitados, recursos metodológicos e acompanhamento especializado (JORGE, et al. 2015).

O Plano Nacional de Educação 2014-2024 traz 10 diretrizes e 20 metas, entre as

\footnotetext{
${ }^{1}$ Graduanda em Fisioterapia, Universidade do Vale do Itajaí, UNIVALI, Brasil. E-mail: jacyvanini@outlook.com.

2 Graduanda em Fisioterapia, Universidade do Vale do Itajaí, UNIVALI, Brasil. E-mail: tatianislesaczek@gmail.com.

3 Doutora em Educação Cientifica e Tecnológica, Universidade do Vale do Itajaí, UNIVALI, Brasil. E-mail: fhcfisio@hotmail.com.

Revista Univap - revista.univap.br
}

São José dos Campos-SP-Brasil, v. 24, n. 46, dez. 2018. ISSN 2237-1753 
diretrizes estão a melhoria da qualidade de educação e a valorização dos profissionais da educação. A meta 4 objetiva universalizar para a população de quatro a dezessete anos, com deficiência, transtornos globais do desenvolvimento e altas habilidades ou superdotação, bem como o acesso à educação básica e ao atendimento educacional especializado, preferencialmente na rede regular de ensino, com a garantia de sistema educacional inclusivo, de salas de recursos multifuncionais, classes, escolas ou serviços especializados, públicos ou conveniados. Essa meta tem várias estratégias, a terceira é a de fomentar a formação continuada de professores e professoras para o atendimento especializado nas escolas e a $13^{a}$ estratégia é a de garantir a oferta de professores (as) do atendimento educacional especializado, profissionais de apoio ou auxiliares (BRASIL, 2014).

Há uma grande incompreensão, por parte da comunidade, sobre a realidade de vida das pessoas com deficiência. Elas convivem com imensas barreiras educacionais, sociais, culturais e arquitetônicas criadas pela sociedade. Legalmente, a inclusão escolar tem como base o artigo 208 da Constituição Brasileira, no qual especifica que é dever do Estado garantir "atendimento educacional especializado aos portadores de deficiência, preferencialmente na rede regular de ensino", condição que, também, consta no artigo 54 do Estatuto da Criança e do Adolescente (ECA).

A legislação também obriga as escolas a terem educadores de ensino regular preparados para atuar com alunos com necessidades especiais. Ou seja, uma criança com deficiência não precisa procurar uma escola especializada, ela tem direito a cursar instituições comuns, sendo dever dos educadores elaborarem e aplicarem atividades que levem em conta as suas necessidades específicas. Para atuarem no processo de inclusão escolar e para que o educador consiga elaborar e aplicar as atividades, é necessário que estejam bem preparados.

Na perspectiva da educação inclusiva para o público da educação especial, os apoios centrais reúnem os serviços da educação especial e o atendimento educacional especializado (AEE). São esses os novos recursos que precisam ser incorporados à escola. $O$ aluno tem direito a frequentar o AEE no período oposto às aulas. $O$ sistema público tem organizado salas de recursos multifuncionais ou salas de apoio, na própria escola ou em instituições conveniadas, com o objetivo de oferecer recursos de acessibilidade e estratégias para eliminar as barreiras, favorecendo a plena participação social e o desenvolvimento da aprendizagem. E ainda que não apresente números consideráveis, a inclusão tem sido incorporada e revela ações que podem ser consideradas práticas para apoiar o professor.

Ter um segundo professor na sala de aula, é um exemplo, seja presente durante todas as aulas ou em alguns momentos, nas mais diversas modalidades: intérprete, apoio, monitor ou auxiliar. Esse professor poderá possuir formação específica, básica ou poderá ser um estagiário. A participação do professor do AEE poderá ocorrer na elaboração do planejamento e no suporte quanto à compreensão das condições de 
aprendizagem dos alunos, como forma de auxiliar a equipe pedagógica (ALONSO, 2013).

Diante das situações legais e educacionais, os agentes de educação inclusiva são atores considerados de suma importância no contexto escolar e no processo de ensino e da aprendizagem, pois estão em contato direto com essa criança, constituindo-se do meio de disseminação do conhecimento, além de serem os facilitadores no processo de ensino-aprendizagem. Considera-se que a formação desse profissional pode influenciar, de diversas maneiras, sua atuação no âmbito da sala de aula (TAVARES; SANTOS; FREITAS, 2016).

A formação dos agentes de educação inclusiva constitui a base do desempenho e da preparação para situações que advirão em seu cotidiano, influenciando, diretamente, portanto, a concepção do agente de educação inclusiva sobre o processo de inclusão escolar. Essa concepção reflete o modo de ver e pensar a educação inclusiva, isto é, os saberes docentes, o saber da experiência, o saber do conhecimento e o saber pedagógico. O saber da experiência é o saber que constrói a base de elementos que irão nortear a prática. O saber do conhecimento envolve a revisão da função da escola na disseminação dos conhecimentos e as suas especialidades num contexto contemporâneo. O saber pedagógico, que compreende o conhecimento aliado ao saber da experiência e dos conteúdos específicos, e que será construído a partir das necessidades pedagógicas reais (PIMENTA, 2009).

Diante do contexto histórico e da formação, este estudo questiona quais os significados atribuídos pelos agentes de educação inclusiva ao do processo de educação inclusiva? Portanto, este trabalho tem como objetivo analisar as concepções dos agentes de educação inclusiva sobre o processo de inclusão escolar dos alunos com deficiência física e intelectual nas escolas de ensino regular de um município da região do Vale do Itajaí-SC.

\section{DESENVOLVIMENTO}

A pesquisa possui caráter qualitativo, exploratória e de campo. O trabalho possui financiamento pela Fundação de Apoio a Pesquisa Científica e Tecnológica do Estado de Santa Catarina (FAPESC) e pelo Programa Institucional de Bolsas à Iniciação Científica (ProBIC).

O campo de estudo foi o município de Itajaí, Santa Catarina, situado a 97 quilômetros de Florianópolis, a capital do Estado. Colonizada por portugueses, no século XVIII, e alemães no século XIX, a cidade tem, desde os seus primórdios, uma forte ligação com a navegação e hoje abriga um dos maiores complexos portuários do país, o Porto de Itajaí. O município foi escolhido por ter uma Secretaria Municipal de Educação preocupada e envolvida com os agentes de educação inclusiva. 
O cenário escolhido para a pesquisa forma as escolas da rede municipal de ensino de Itajaí. Esta é constituída por 113 escolas, sendo 7 centros educacionais em tempo integral, 66 centros de educação infantil, 3 centros educacionais, 28 escolas básicas, 5 escolas isoladas e 4 grupos escolares. As escolas selecionadas para a pesquisa são as que possuem alunos com deficiência regularmente matriculados no ensino fundamental e, consequentemente, agentes de educação inclusiva locados nas salas de recursos multifuncionais (SRMs).

Os participantes do estudo constituíram uma amostra intencional dos agentes de educação inclusiva das salas de recursos multifuncionais, intérpretes de língua de sinais e agentes de educação especial (AEE) dos alunos com deficiência de uma na rede municipal da região do Vale do Itajaí/SC. Os critérios de inclusão foram: serem professores das salas de recursos multifuncionais, intérpretes de língua de sinais e agentes de educação especial (AEE) da rede de ensino municipal de Itajaí, que atuam na educação com alunos que possuem algum tipo de deficiência. $E$ os critérios de exclusão: professores que não são da rede municipal de Itajaí e não tiverem alunos com deficiência em suas salas, professores de ensino regular e aqueles que não aceitaram em participar da pesquisa e não assinaram o Termo de Consentimento Livre e Esclarecido (TCLE).

A técnica de coleta dos dados foi a entrevista semiestruturada. Com o intuito de não atrapalhar a rotina da escola e dos professores, as entrevistas ocorreram na escola, em horários estabelecidos pela direção e estavam presentes somente a pesquisadora e o entrevistado. As questões norteadoras da entrevista se referiram à formação acadêmica e continuada, tempo e experiência na área de educação inclusiva, à concepção sobre Inclusão Escolar, à definição de deficiência, o que considera adequado e inadequado e, por fim, às facilidades e dificuldades no processo de inclusão escolar. As entrevistas foram gravadas em gravador de voz e, posteriormente, transcritas com alunos que possuem algum tipo de deficiência.

Após as transcrições das entrevistas, os dados foram examinados por meio da análise de conteúdo de análise Bardin (2011). A análise de conteúdo é um dispositivo apto para o tratamento da informação recolhida pela capacidade de promover a multidimensionalidade dos fenômenos, por intermédio das falas produzidas pelos autores, permitindo um desvendar crítico. A conceitualização da análise de conteúdo pode ser concebida de diferentes formas, tendo em vista a vertente teórica e a intencionalidade do pesquisador que a desenvolve, seja adotando conceitos relacionados à semântica estatística do discurso, ou, ainda, visando à inferência por meio da identificação objetiva de características das mensagens. Esse processo de análise contribuiu para compreendermos o processo de inclusão escolar na ótica dos educadores inclusivos dos alunos com deficiência.

Os preceitos éticos da resolução 466/12 foram seguidos e a coleta de dados só iniciou após a aprovação na Comissão de Ética, conforme parecer número 1.134.168. 
Portanto, as entrevistas aconteceram no período de março a agosto/2016. A fim de manter o anonimato as participantes receberam o codinome "educadoras" seguido de numerais.

Participaram do estudo oitenta agentes de educação inclusiva das trinta e seis escolas da rede municipal de Itajaí, sendo, entre elas, seis centros educacionais integrados (CEI), vinte e oito escolas de educação básica e dois centros de educação em tempo integral (CEDIN).

Os resultados serão apresentados em duas etapas: a primeira quanto à caracterização dos participantes; e a segunda, quanto às concepções das educadoras sobre o processo de inclusão escolar.

\subsection{Quem são as agentes de educação inclusiva?}

As educadoras inclusivas destacam-se na predominância de serem do sexo feminino. De acordo com Vasconcelos e Felix (2013), a Lei de 1827 possibilitava o ingresso, nas escolas, das mulheres, tanto alunas quanto mestras, e o acesso à instrução, a partir das regras descritas neste artigo. Essas mulheres sairiam do espaço privado para o público, somente para retornar para a casa (privado), um pouco mais especializadas. Vianna (2013) aponta para uma maioria absoluta de mulheres na Educação Infantil, com 97,9\% de mulheres (97,9\% para creches e 96,1\% para préescolas). O Ensino Fundamental ainda indica a presença majoritária de $82,2 \%$ de mulheres, mas, aqui, com distinções significativas quanto aos anos iniciais $(90,8 \%)$ e finais $(73,5 \%)$.

No que se refere à sua formação acadêmica, 55 educadoras possuem graduação, cinco têm magistério, 18 ensino médio completo, uma ensino médio incompleto e apenas uma não respondeu. Quanto à formação continuada em inclusão, os resultados apontam que 66 educadoras possuem formação continuada, 13 não a possuem e uma não respondeu.

$\mathrm{Na}$ Educação Especial, os debates em torno da formação do professor responsável pelo atendimento educacional escolarizado de alunos que apresentam deficiência vão desde reuniões pedagógicas realizadas nas unidades escolares até a definição de políticas públicas de educação, passando por reflexões teóricas e proposições acadêmicas. Segundo Gatti (2016), a formação continuada, oferecida sob várias condições, ou procurada em vários contextos pelos próprios professores, dão conta, porque estes tentam encontrar novos caminhos e mais fundamentos e meios para seu desempenho profissional.

Quanto à experiência na educação especial, três delas relatam ser a primeira experiência de emprego, três trabalham com essa ocupação há um ano, nove trabalham 
há dois anos e 65 delas trabalham há mais de dois anos, com suas ocupações específicas na educação especial.

De acordo com Melo e Ferreira (2009), o cuidar e o educar caminham simultaneamente e de maneira indissociável, possibilitando que ambas as ações construam, na totalidade, a identidade e a autonomia.

Ressalta-se, aqui, a importância de uma postura relacional do professor para com seus alunos, postura esta que coloca o educador muito acima de um mero executor do currículo oficial. A educação só tem sentido quando valoriza o ser humano, as suas vivências e os seus sentimentos, construindo o saber e ajudando as pessoas a tornarem-se mais livres e menos dependentes do poder econômico, político e social (CANAL, et al. 2015).

Um professor empenhado na inclusão contribui para a qualidade dos processos educativos, difundindo sentimentos positivos a todos os que o rodeiam. Essas atitudes são rapidamente detectadas e adotadas pelos alunos, sendo a criação de um ambiente positivo e confortável essencial para que a experiência educativa tenha sucesso e seja gratificante para todos (FERREIRA, et al. 2015).

Quanto à experiência na educação especial, 67 educadoras já possuem experiência nessa área, 11 não apresentam experiência nessa área e apenas duas não responderam essa questão.

Segundo Sampaio (2015), todos os cursos de formação de professores, do magistério às licenciaturas, devem dar-Ihes a consciência e a preparação necessárias para que recebam, em suas salas de aula, alunos com e sem necessidades educativas especiais, dentre os quais alunos com deficiência.

[...] devem preparar esses profissionais de modo que possam prestar atendimento educacional especializado, em escolas comuns e em instituições especializadas, envolvendo conhecimentos como: código de Braile, Libras, técnicas que facilitem o acesso de pessoa com deficiência ao ensino em geral, e outros com a mesma finalidade. (SAMPAIO, 2015, p. 19).

A formação continuada do professor apodera-se de uma definição ímpar, no que diz respeito à condição para a aprendizagem permanente e para o desenvolvimento pessoal, cultural e profissional de professores e especialistas.

\subsection{Quais as concepções das educadoras sobre a educação inclusiva?}

A partir do entrelaçamento dos núcleos de sentidos encontrados e posterior confronto entre esse material e os pressupostos teóricos estudados, realizou-se uma análise crítica do estudo, englobando os objetivos, o que possibilitou a construção de categorias constituintes empíricas. As categorias empíricas constituintes do estudo 
estão aqui descritas: inclusão de todos, Inclusão Longe do ldeal e Real, falta de recursos humanos e estrutura física para inclusão.

\subsection{Inclusão de Todos}

Tais aspectos são fundamentais para que a inclusão de alunos com necessidades educacionais especiais seja realizada com sucesso. Entender as diferenças e conviver com elas proporciona experiências significativas que, certamente, contribuirão para o desenvolvimento desses sujeitos (OLIVEIRA; FISCHER, 2015).

Nesse sentido, as educadoras relatam que a inclusão é de todos, observado nas unidades de registro, abaixo.

\footnotetext{
A inclusão é de todos. Incluir significa ter um olhar plural na singularidade (educadora 2).

A inclusão do meu ponto de vista se refere a todas as diversidades. Isto é pensar em todos os alunos, que devem estar no processo incluído de acordo com suas necessidades, aprendemos de formas diferentes (educadora 60).

Inclusão escolar é a maneira que incluímos todos os cidadãos independente de qualquer diferença que possuem (educadora 79).
}

O ser humano, ao nascer, dispõe apenas de recursos biológicos característicos da espécie, que podem ser considerados a base para o processo de humanização. Mas é a convivência com o outro que vai possibilitar que esse processo se concretize. É por meio dessas interações que irá se constituir como ser humano (MENEZES; CASTRO, 2016).

Mais do que criar condições para os alunos com NEE, a inclusão é um desafio que implica em mudar a escola por inteiro, valorizando o aluno e suas particularidades, incorporando a diversidade, atendendo a todos em seu meio, sem nenhum tipo de distinção (SALDANHA; GARCIA; ZAUPA, 2015).

\subsection{Inclusão Longe do Ideal e do Real}

Embora a inclusão escolar seja contemplada em Lei e tenha como meta recuperar toda uma história de segregação, isolamento, discriminação e preconceito, sua prática está longe deste ideal (FREITAS; CARVALHO, 2016). As afirmações abaixo ilustram a visão das educadoras.

Acredito na inclusão, embora não vejo que realmente seja aplicada da forma que deveria ser (educadora 3). 
A inclusão está muito longe de ser o ideal, por falta de interesse pelos professores, incompreensão dos pais dos outros alunos e pela falta de cobrança na escola (educadora 19).

Inclusão escolar, para mim, ela precisa sair dos papéis e começar na prática (educadora 52).

Gostaria que funcionasse melhor esse termo inclusão, dentro da unidade, dependendo do caso, acontece exclusão por parte de alguns alunos e por alguns profissionais (educadora 68).

Não existe inclusão! Ainda falta no geral, principalmente pela parte de alguns profissionais (educadora 77 ).

Dessa forma, o movimento de inclusão traz, como proposta inicial, propiciar a educação para todos, uma vez que o direito do aluno com deficiência e de todos os cidadãos à educação é um direito constitucional. No entanto, observa-se que a realidade desse processo inclusivo ainda é bem diferente do que se propõe na legislação e requer ainda muitas discussões relativas ao tema. O que se percebe é que, numa comparação entre a legislação e a realidade educacional, a inclusão dos alunos, público da educação especial, no ensino regular não se consolidou da forma desejada.

Segundo Sassaki (2006), para essas mudanças deverá ser levado em conta o contexto socioeconômico, além de serem gradativas, planejadas e contínuas para garantir uma educação de ótima qualidade. Por outro lado, o processo de inclusão já está posto e não se trata de desativar o que está funcionando, mas de buscar alternativas e formas de articulações que possibilitem esse novo modo de ver e pensar sobre a escola.

Como afirma Santos (1995, p. 38)

Há diferenças e há igualdades, e nem tudo deve ser igual nem tudo deve ser diferente, [...] é preciso que tenhamos o direito de ser diferente, quando à igualdade nos descaracteriza e o direito de ser iguais quando à diferença nos inferioriza.

\subsection{Falta de Recursos Humanos e Estrutura Física para Inclusão}

Numa escola inclusiva, o papel de cada educador é considerado um recurso rico para a troca de experiências com o objetivo de aperfeiçoar a prática docente e de todos os envolvidos. Sobre essa formatação, Mantoan (2006, p. 36) destaca que:

[...] todo plano de formação deve servir para que os professores se tornem aptos ao ensino de toda a demanda escolar. Dessa forma, seu conhecimento deve ultrapassar a aceitação de que a classe comum é, para os alunos com necessidades especiais, um mero espaço de socialização.

A preocupação com a aprendizagem dos estudantes também se constitui como um pilar à ação educacional inclusiva. O professor assume o relevante papel de provocar a aprendizagem significativa, em seus discentes, em uma perspectiva 
dialógica, formativa e mediadora, despertando, neles, o desejo pelo conhecer e a necessidade do saber, para o saber ser, incrementando sua autonomia e respeitando a capacidade e o direito de escolha, aumentando sua participação nas decisões que the afetam (MARTINS, 2016).

Nessa situação, as educadoras em questão mostram desapontamentos em alguns pontos:

Falta de incentivo como formação continuada etc. (educadora 1).

Professores sem formação, espaço diferenciado e adaptado (educadora 5).

Falta de acessibilidade na escola e formação para os professores e agentes de educação especial (educadora 34).

A falta de preparação dos profissionais (educadora 42).

Todas possíveis. Falta de formação e ambiente adequado seria algumas delas (educadora 46).

É enorme a responsabilidade de professores e profissionais da educação. Eles têm de dar resposta a múltiplas tarefas, e promover as aprendizagens dos seus alunos, contribuindo para o seu desenvolvimento pleno, sem esquecer que devem considerar as suas caraterísticas pessoais e sociais.

Para responder a esses desafios e às diferentes visões da escola, também a formação de professores se torna um processo complexo. Pensar a formação dos professores/educadores exige ter em conta a realidade da escola e as funções que têm de assumir os docentes, a quem se exige um amplo perfil de competências.

De acordo com as respostas citadas pelas educadoras, as quais citam bastante dificuldade quanto à infraestrutura das escolas em que atuam, como descrito abaixo.

No contexto geral, falta estrutura física nas escolas para atender crianças com necessidades especiais, principalmente cadeirantes (educadora 17).

A principal é a falta de uma estrutura física das escolas (educadora 24).

Material, valorização do profissional, incentivo, conscientização da família, cursos, interação dos agentes com a família, escola... Inclusão de fato (educadora 28).

$\mathrm{Na}$ função como educadora inclusiva, encontro muitas dificuldades com os pais, eles apresentam resistência ao nosso trabalho e muito pouca informação sobre qual é a verdadeira função (educadora 39).

Espaço físico inadequado e falta de conhecimento específico (educadora 45).

Estrutura das escolas e preparação profissional (educadora 67). 
A falta de conhecimento dos pais. Os pais, muitas vezes, não sabem, nem entendem o que acontece com o filho. Acredito que deveriam ser feitas reuniões, palestras, para deixar os pais cientes (educadora 80).

Percebe-se que, além da infraestrutura, há grande desconforto e insatisfação das profissionais quanto à participação do grupo familiar na inclusão dessas crianças. Santos e Oliveira (2015) afirmam que o nascimento de um novo membro é sempre um momento de expectativas e de reestruturação da teia familiar. Dá-se início a um lento e progressivo movimento de preparação do espaço familiar para a chegada desse novo ser, ocorrendo mudanças nas esferas emocional, comportamental, física, social e econômica. Contudo, a chegada de uma criança com deficiência gera uma infinidade de sentimentos contraditórios que implicaram em mudanças profundas em sua forma de ser, tornando-se um acontecimento traumático, envolto por um clima de muitas incertezas e confusões. Esse momento irá influenciar na construção da identidade do grupo familiar e, consequentemente, na de seus componentes.

Na maioria das vezes, compreensão dos pais por falta de informações, de limites dos seus filhos (educadora 9).

Várias dificuldades, começando pela família, passando pelo corpo docente da escola e pela falta de estrutura física adequada ao aluno com deficiência (educadora 15).

Quando estimuladas adequadamente, de forma sistemática, pode haver bons resultados, daí a importância da família, no processo, desde o nascimento da criança. É visível a importância da família nos processos de aprendizagem e conquista da autonomia por parte da criança (CRUZ, 2015).

\section{CONSIDERAÇÕES FINAIS}

O princípio inicial deste trabalho foi de analisar as concepções do processo de inclusão escolar dos alunos com deficiências, a partir da visão que os educadores inclusivos das escolas de ensino regular pré-selecionadas possuíam acerca destas.

Quando analisado de uma forma mais crítica, observa-se que as dificuldades existem e que elas não são poucas, que a inclusão não é apenas fazer com que o aluno esteja situado dentro de uma sala regular.

Ao realizar a entrevista com as educadoras, pôde-se observar que a grande maioria delas possui formação superior, formação continuada e atualização de cursos recentemente. Além disso, a maioria também trabalha com essa função há mais de dois anos e trabalha com crianças com deficiência múltipla, mas, mesmo assim, apesar de teoricamente possuírem vasta experiência na área, relatam não se sentirem preparadas 
e consideram que os recursos físicos que são disponibilizados não conseguem suprir as necessidades das crianças e/ou da sua função.

Mesmo referindo-se a essas dificuldades, observa-se que, entre todas as educadoras, havia algo imprescindível, que é capaz de ultrapassar todas as barreiras que encontram ao longo da caminhada, e isso nos foi relatado e demonstrado por intermédio da amorosidade pela profissão e pelas crianças. Apesar da quantidade de barreiras, de limites e de todo e qualquer preconceito, essas profissionais mostram-se firmes diante dos seus ideais. Que, apesar de toda insegurança, medo e falta de preparo, estão sempre dispostas a "encarar" o novo e não desistem.

\section{REFERÊNCIAS}

ALONSO, D. Os desafios da educação inclusiva: foco nas redes de apoio. Nova Escola. 2013. Disponível em: <http://revistaescola.abril.com.br/formacao/palavraespecialistadesafios-educacao-inclusiva-foco-redes-apoio-734436.shtml>. Acesso em: 06 abr. 2017.

BARDIN, L. Análise de conteúdo. São Paulo: Edições 70, 2011.

BRASIL. Planejando a Próxima Década: Conhecendo as 20 Metas do Plano Nacional de Educação. Brasília: [s.n], 2014.

CANAL, T. et al. Amor e ética no cotidiano do professor. Revista Maiêutica, v. 3, n. 1, p. 7-12, 2015.

CRUZ, C. N. da. Relações familia-escola na educação e no desenvolvimento intelectual de uma criança com diagnóstico de síndrome de espectro autista. 2015. 42 f. Monografia (Especialização) - Universidade de Brasília - Unb, Brasília, 2015.

FERREIRA, M. et al. Educação inclusiva: o professor como epicentro do processo de inclusão. Revista Nacional e Internacional de Educación Inclusiva, v. 8, n. 1, p. 1 13, 2015.

FREITAS, E. A.; CARVALHO, L. M. C. P. A história e os desdobramentos da inclusão de portadores de necessidades especiais na rede regular de ensino. ANAIS DO SCIENCULT, v. 1, n. 3, 2016.

GATTI, B. A. Formação de professores: condições e problemas atuais. Revista Internacional de Formação de Professores (RIPF), v. 1, n. 2, p.161-171, 2016.

JORGE, M. L. D. et al. Educação Inclusiva e a implementação das Salas de Recursos Multifuncionais. Id on Line Revista de Psicologia, v. 9, n. 25, p. 62-90, fev. 2015.

MANTOAN, M. T. E. Igualdade e diferença na escola: como andar no fio da navalha. In: MANTOAN, M. T. E.; PIETRO, R. G. (orgs). Inclusão escolar: pontos e contrapontos. São Paulo: Summus, 2006. 
MARTINS, L. M. S. M. Práticas e formação docente na UFRN com visitas à inclusão de estudantes cegos. 2016. 140 f. Tese (Doutorado) - Curso de Pósgraduação em Educação, Universidade Federal do Rio Grande do Norte, Natal, 2016.

MELO, F. R. L. V.; FERREIRA, C. C. A. O cuidar do aluno com deficiência física na educação infantil sob a ótica das professoras. Rev. Bras. Ed. Esp., v. 15, n. 1, p.121140, 2009.

MENEZES, E. C. P.; CASTRO, S. F. Ações da Educação Especial no contexto da escola regular: problematizações sobre a inclusão de alunos com deficiência intelectual. Linhas, v. 17, n. 35, p. 30-44, 2016.

OLIVEIRA, V. C. de; FISCHER, J. Práticas pedagógicas na educação física: cooperando e dançando de mãos dadas, buscando a inclusão escolar. Professare, v. 4, n. 3, p. 157-176, 2015.

PIMENTA, S. G. Saberes pedagógicos e atividades docente. 7. ed. São Paulo: Cortez, 2009.

SALDANHA, S. N.; GARCIA, C. A. X.; ZAUPA, P. A Inclusão de crianças com necessidades educacionais especiais na prática pedagógica de uma escola municipal do município de Vila Nova do Sul. Monografias Ambientais, v. 14, p. 143-154, 2015.

SAMPAIO, P. A. S. R. Integração de quadros interativos no ensino da matemática desenvolvimento profissional de professores. Educ. Matem. Pesq., v.17, n.1, p. 25-44, 2015.

SANTOS, A. C. A.; OLIVEIRA, V. M. S. A família como elemento para a inclusão social do deficiente. Ideias \& Inovação, v. 2, n. 2, p. 47-58, 2015.

SANTOS, B. DE S. Entrevista com Prof. Boaventura de Souza Santos, (On Line). 1995. Disponível em: <http://www.dhi.uem.br>. Acesso em: 07 ago. 2017.

SASSAKI, R. K. Inclusão: construindo uma sociedade para todos. 7. ed. Rio de Janeiro: WVA, 2006.

TAVARES, L. M. F. L.; SANTOS, L. M. M.; FREITAS, M. N. C. A Educação Inclusiva: um Estudo sobre a Formação Docente. Revista Brasileira de Educação Especial, v. 22, n. 4, p. 527-542, 2016.

VASCONCELOS, M. C. C.; FELIX, I. O. Histórias de vida: mulheres professoras e a escolha do magistério. Indagatio Didactica, v. 5, 2013.

VIANNA, C. P. A feminização do magistério na educação básica e os desafios para a prática e a identidade coletiva docente. In: YANNOULAS, S. C. (Org.). Trabalhadoras: análise da feminização das profissões e ocupações. Brasília, DF: Abaré, 2013. p. 159180. 